\title{
Investigating Student Use of Electronic Support Tools and Mathematical Reasoning
}

\author{
Kristina N. Higgins \\ Tarleton State University, United States \\ Lindy Crawford \\ Texas Christian University, United States \\ Jacqueline Huscroft-D'Angelo \\ University of Nebraska-Lincoln, United States \\ Mark Horney \\ University of Oregon, United States
}

\begin{abstract}
Mathematical reasoning involves comprehending mathematical information and concepts in a logical way and forming conclusions and generalizations based on this comprehension. Computer-based learning has been incorporated into classrooms across the country, and specific aspects of technology need to be studied to determine how programs are influencing student reasoning and learning. This article explores how one aspect of computer-based learning, electronic support tools (ESTs), influences students' mathematical reasoning over the course of an online supplemental mathematics program, the Math Learning Companion (MLC). Students in Grades 3, 4, and $5(N=31)$ from two private schools participated in MLC, and their reasoning was assessed before and after participating in the program. EST use was measured by using frequency counts for each tool. Results describe students' tool use and reflect an overall change in their reasoning over the course of the intervention, indicating that students use ESTs as needed to individualize the learning program. Students specifically used ESTs as needed to improve their mathematical reasoning, their correctness of response, and their mathematical explanations of their answers over the course of the intervention.
\end{abstract}

Keywords: Mathematical reasoning; Computer-based instruction; Electronic support tools; Mathematics education

\section{Introduction}

Despite being one of the wealthiest countries in the world, mathematics proficiency of students in the United States, as measured by the Programme for International Student Assessment (PISA), lags behind the performance of students worldwide and has remained stagnant for more than a decade (Organisation for Economic Co-operation and Development [OECD], 2013a), leaving students unprepared for working in a global economy (Hanushek, Peterson, \& Woessman, 2012). 
The availability of educational resources, including computers and software used for instruction along with internet connectivity, explains about one-third of the variance in instruction worldwide (Education Superhighway, 2014; OECD, 2013b), implying that students with more access to educational resources show higher levels of mathematical proficiency. Although students in the United States generally have wide access to educational resources as compared to the rest of the world (OECD, 2013b), according to the U.S. Department of Education's National Education Technology Plan (2010), "the role technology plays in the nation's classrooms varies dramatically depending on the funding priorities of the states, districts, and schools and individual educators' understanding of how to leverage it in learning in meaningful ways" (p. 9). Thus, the lack of change in mathematical proficiency overall indicates a need to further investigate other constructs related to mathematical performance, such as mathematical reasoning, within the context of technology. Specific type of technological tools such as electronic support tools (ESTs), which are often embedded within computer-based educational programs or curricula, should be explored as well as their relationship to improvements in mathematical reasoning.

According to Kilpatrick, Swafford, and Findell (2001), mathematical proficiency can be described as five strands of students' cognitive engagement: conceptual understanding, procedural fluency, strategic competence, adaptive reasoning, and productive disposition. Current research focuses on interventions that address procedural fluency and strategic competence; however, few studies include how students communicate conceptual understanding or adaptive reasoning. Part of becoming proficient in mathematics involves the ability to reason, communicate this mathematical thinking and engage in the process of constructing new knowledge (National Council of Teachers of Mathematics [NCTM], 2000). Furthermore, Dreyfus and Eisenberg (1996), discuss the many facets of thought, which are common to implicit and explicit characterizations of mathematical reasoning such as analogy, representation, visualization, and reversibility of thought. The fundamental processes involved in mathematical reasoning, which include quantification, patterning, abstraction and generalization, and representation and translation are required for students to obtain a sense and understanding of quantity, amount, or number (Dreyfus \& Eisenberg, 1996; English, 2004). Therefore, thoroughly examining how students describe this process and the manner in which they get there through features of the program is critical for identifying and understanding methods in which individuals navigate mathematical problems to arrive at a solution.

Mathematical reasoning can be conceptualized as the ability to understand and make sense of mathematical concepts in a logical way in order to form a conclusion or judgment (National Governors Association Center for Best Practices \& Council of Chief State School Officers [NGA \& CCSSO], 2010; Merriam-Webster, 2014). According to the National Council of Teachers of Mathematics' [NCTM] Guiding Principles (2000), "being able to reason is essential to understanding mathematics" (p. 3). Reasoning provides students with the ability to comprehend all other aspects of mathematics as individuals recognize that mathematical skills and concepts make sense by exploring patterns or regularities, synthesizing information, and providing arguments to support their conclusions (NCTM, 2000; Rosenstein, Caldwell, \& Crown, 1996). However, teachers often underestimate students' mathematical reasoning abilities, and subsequently these abilities are underutilized as a pathway to mathematical understanding by both teachers and students (Francisco \& Maher, 2010). 
The Standards for Mathematical Practice outlined in the Core Curriculum State Standards for Mathematics (CCSSM) emphasize the conceptual understanding of mathematics and mathematical reasoning along with procedural fluency and problem-solving, as well as encourage the use of technology and tools within the classroom to further mathematical understanding (NGA \& CCSSO, 2010). The CCSSM process standards are derived from both the NCTM's (2000) process standards, which include problem solving, reasoning and proof, communication, representation, and connections, and Kilpatrick, Swafford, and Findell's (2001) five strands of mathematical proficiency: adaptive reasoning, strategic competence, conceptual understanding, procedural fluency, and productive disposition. Given that commonalities exist between the CCSSM and the PISA, it is plausible to assume that rigorous implementation to the CCSSM standards, including an emphasis on mathematical reasoning and the use of technology in the classroom, will improve students' mathematical proficiency related to global standards over time (OECD, 2013a).

Many technologies (e.g. computer software including gaming or skill-based, web-based programs, videos) have been shown to enhance reasoning and higher level thinking (O'Donnell, 2006; D'Angelo, Higgins, \& Crawford, in press). Kramarski and Zeichner (2001) show how metacognitive feedback from a computer-based program can enhance student reasoning in mathematics over and above simple result-based feedback. This research replicated an earlier study with the same findings in a non-computerized environment (Mevarech \& Kramarski, 1997), illustrating the influences of metacognitive feedback on mathematical reasoning both within and outside of the context of computer-based learning. Yian-Shu, Haw-Ching, Shian-Shyong, and Che-Ching (2014) demonstrated the effectiveness of computer-based intelligent tutors on improving students' reasoning and problem-solving skills. The programs used in this study gauged the students' strengths and weaknesses and adapted to the students' needs. These studies demonstrate the ability of computer-based environments to improve reasoning; however, little is known about how specific aspects of technology may be directly related to reasoning improvement.

Many computer-based instructional programs include electronic support tools (ESTs) embedded as features of the program that the users must choose to implement (Crawford \& Freeman, 2011). Most literature on ESTs involves literacy (Anderson-Inman \& Horney, 1996; Englert, Manalo, \& Zhao, 2004); however, students use electronic tools in mathematics as well, such as embedded calculators, pop-up mathematical formulas, or audio support. Aleven, McLaren, Roll, and Koedinger (2006) found that when students used "hint requests" - a specific type of support tool students' mathematical learning improved over the course of the program. Crawford, Higgins, D'Angelo, \& Hall (under review) found that the students with lower academic skill scores prior to beginning an online program used more ESTs and students with higher academic skill scores used fewer ESTs; however, all students showed improvement over the course of the program. This demonstrates how students of differing abilities can use ESTs to individualize online learning. Furthermore, in a cross-case analysis, Crawford, Higgins, and Freeman (2012) examined how students with disabilities maximized the use of an online learning program by tailoring the instruction to their own needs through the availability and implementation of ESTs. For example, one student diagnosed with dyslexia used an audio support feature throughout the program, and another student who had a specific learning disability in mathematics described how the dictionary was helpful. These students used different tools to individualize the program to their specific learning needs. 
Given the need to understand how different aspects of technology relate to mathematical reasoning and understanding, the current study explores the potential effects of ESTs on changes in students' mathematical reasoning over the course of an online supplemental mathematics curriculum. This program was delivered through a website and occurred outside of core mathematics instruction (whole class, teacher-led instruction). This research seeks to specifically answer the following questions:

1. To what extent are students using electronic support tools to support their learning in a digital environment?

2. In what ways are students' frequency of tool use related to their correctness of responses, mathematical explanations, and mathematical reasoning?

\section{Methodology}

\section{Participants}

Participants included students in third, fourth, and fifth grade $(N=31)$ and were recruited from two private schools located in North Texas. One school focused on students with learning differences ${ }^{1}$, and all of the students in the third $(n=7)$ and fourth $(n=8)$ grade class participated in this study. One of the fourth grade students did not complete the program because he left the school; therefore, fourteen students were included from the private school for students with learning differences. Furthermore, a general education private school also participated in this study. In this school, all but one student in the third grade class $(n=9)$ participated, and eight students in the combination fourth/fifth grade class participated as well (fourth grade, $n=5$; fifth grade, $n=3$ ). Between both schools and all grade levels, thirty-one students total completed the program.

Overall, eighteen boys and thirteen girls participated in the study. Well over three-fourths of the sample were Caucasian and the rest of the sample consisted of African American $(n=3)$, Asian ( $n=$ $1)$ and multiracial $(n=1)$ participants. Slightly more than one third of the sample $(n=11)$ was verified with a primary eligibility category of learning disability, six students were verified with 'Other Health Impairment' (e.g. ADHD, anxiety), two students were verified with autism, one student was verified with a speech/language impairment, and one student was verified with emotional disturbance.

All participants received instruction in English, and only one qualified for free/reduced lunch (meaning most students were from a moderate to high socioeconomic status). Teachers reviewed student files and reported demographic information through a checklist.

\footnotetext{
${ }^{1}$ Students with learning differences vary from students with diagnosed learning disabilities, students with emotional or behavioral problems, or students who have some other condition that prevents them from learning in a traditional classroom setting.
} 


\section{Math Learning Companion}

The Math Learning Companion (MLC; Digital Directions International [DDI], 2013) program is designed as a supplemental online mathematics curriculum for students in Grades 3-8 who are low-performing in mathematics. MLC consists of 73 lessons within seven modules: Math Foundations 1, 2, and 3; Number Sense; Algebra; Geometry; and Data Analysis. Students' advance through each lesson by completing the following lesson components: (1) Real World (instructional set), (2) Vocabulary (introduction of new mathematical terms), (3) Instruction (explicitly delivered), (4) Try It (guided practice), (5) Game (independent practice), and (6) Quiz (10-items randomly selected that align with lesson content). The MLC curriculum framework is modeled after HELPMath@ (DDI, 2005), which shows positive effects on an ELL population (Tran, 2005), and in 2012 met the What Works Clearinghouse criteria without reservations for a single subject study. For the purpose of this study, the teachers assigned their class a curriculum sequence of eight lessons that closely aligned with the current classroom curriculum.

\section{Measures}

\section{Math Reasoning Inventory}

The Math Reasoning Inventory (MRI; Burns, 2012) is a formative assessment involving face-to-face interviews focusing on core numerical reasoning strategies to assess mathematical reasoning. This measure was chosen because it is one of the few measures available that examines mathematical reasoning aligned the work of Kilpatrick et al. (2001) and the CCSS, which was used as a resource for considering the conceptualization of mathematical reasoning. The theory behind the MRI was related to two main dimensions content and cognitive engagement. Cognitive engagement is considered as essential dimension for mathematical proficiency as noted in the work of Kilpatrick et al. (2001) and is discussed in detail in the technical manual (Bernbaum Wilmont, 2012). It is represented in the MRI as "the process through which students are expected to strategize, rationalize, and reason" (Bernbaum Wilmont, 2014, p 4).

The Whole Numbers portion of the MRI was used for this study; this consisted of 10 items in which participants were provided a problem, asked to answer the problem without the use of pencil and paper, and then asked, "How did you figure this out?" Researchers recorded students' verbatim responses, and these responses were used to analyze participants' reasoning skills. The Whole Numbers test reliability includes a Cronbach's alpha of .81, and the individual questions have Point-Biserial correlation coefficients ranging from .38 -.53 (Bernbaum Wilmot, 2012). The MRI is normed for students in the $4^{\text {th }}$ through $8^{\text {th }}$ grade; although we used data from students in Grade 3 , we verified with the teachers that the content covered in the Whole Number portion of the MRI had been covered at some point during the academic year. Thus, it was given across the grade levels of this study. Before administering this measure, interventionists watched instructional videos on administering the MRI available through the MRI website, after which practice sessions of delivering and scoring the MRI were conducted. 


\section{EST Use}

The specific ESTs within the MLC program include: a calculator, a key terms dictionary, a link to formulas, audio support, a 'need more help' button, a notepad, and a social media wall. The calculator assists with basic algorithmic functions, but has no scientific or graphing capabilities. The audio support will read aloud all of the text on the given screen for every page of MLC (the lessons, quizzes, within the dictionary, etc.) in both English and Spanish. The key terms dictionary provides definitions for all mathematically-related terms in MLC; for example, if the student either goes into the dictionary itself or clicks on the hyperlink for the term 'real numbers', they are provided with the definition "All natural, whole, integers, rational and irrational numbers, put together in one set." Students are also provided this definition in Spanish, a visual representation of 'real numbers', and the ability to have this definition read aloud in either language. Within the definition, the terms 'integers', 'rational', 'irrational', 'numbers' and 'together' are also hyperlinked, giving the student the opportunity to explore further definitions at the click of a button. The formula button provides information on all geometric and algebraic formulas along with a visual representation and hyperlinks to the dictionary. For example, if a student needs the formula for the area of a rectangle, they are provided with the formula length $\mathrm{x}$ width, a picture of a rectangle that has 'length' and 'width' denoted, and hyperlinks to the definitions of 'length', 'width', and 'area'. The need-more-help button appears on pages where students must answer questions, and provides the students with more information about the particular concepts presented on that page.

Two of the tools provided are digital writing and communication tools: a notepad and a social media wall. A digital notepad gives users the opportunity to take notes directly in the program and use these on subsequent pages or the quiz (see Figure 1 for a sample notepad entry), and a social media wall allows students to communicate with one another via a blog (see Figure 2 for a sample wall post). Both of these features allow students to either type, write, draw, and/or insert mathematical symbols into their notes or posts. Frequency counts were recorded and downloaded daily each time a student clicked on an EST.

\section{A fraction is a number that describes part of a whole.}

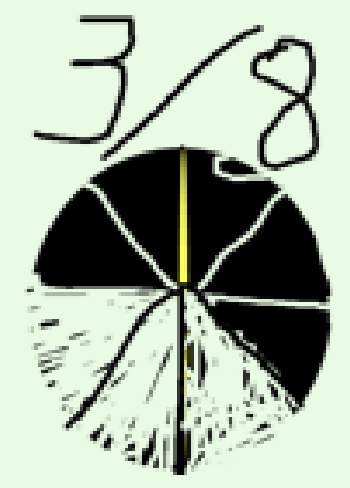

Figure 1. Example of a Student's Entry in the Digital Notepad Using the Typing and Drawing Features 


\section{Math Foundations 2, L3 Negative}

\section{0 isn't a positive or negitive}

\section{Hide Comment Save To My N}

\section{May 092013 07:52:27 AN}

\section{I think it is a mix}

Figure 2. Example of a Student Posting a Statement to the Digital Media Wall (" 0 isn't a positive or negative") and Another Student's Comment on Their Post ("I think it is a mix")

\section{Procedures}

The Principal Investigator (PI) conducted a structured training session for three researchers that included an overview of the goals of the study, specific directions for working with students, opportunities for practice administering measures, and delivering the intervention script. The PI conducted random field observations of all researchers to ensure the fidelity of the implementation of the program.

MLC is intended to be a supplemental curriculum; therefore, researchers provided the teachers ( $N$ $=4$ ) information about each lesson's content. Each teacher selected eight lessons and placed them in order to best align with their mathematics curriculum over the course of the program, which spanned 12 weeks during the second part of the academic year. Two third grade classes completed the same lessons from Math Foundations 1, although they were completed in different order based on the class's curriculum. One fourth grade class completed a combination of lessons from Math Foundations 1 and 2 with varying order, and one combination classroom (five fourth and three fifth graders) completed lessons from Math Foundations 1, 2, 3, and Algebra. See the Appendix A for a complete list of lessons in order for each class.

All students were assessed on the Math Reasoning Inventory (MRI) before the program was introduced and once the program was completed. Before beginning the Math Learning Companion (MLC), students were provided a scripted training on the use of MLC and individual electronic support tools (ESTs). Researchers demonstrated the functions and use of each EST for participants prior to entering the intervention, and students were then given time to practice using each ESTs before engaging in actual lessons. Pretesting and training lasted approximately one week. Participants used MLC twice weekly for 45 minutes and completed a total of 8 MLC lessons outside of their normal mathematics class time for a total of ten weeks. It should be noted that two students did not complete the entire 8 lessons; however, they completed the allotted amount of 
time for the intervention and could not finish due to the school year ending. One week was allotted for post-testing at the end of the year for a total of twelve weeks.

\section{Data Analysis Plan}

Before data analysis of the MRI could occur, data needed to be organized and coded. Three steps were implemented to prepare and code participant data. First, researchers developed a coding dictionary for each of the three components of the MRI (Student Answer, Student Explanation, and Student Reasoning). Student Answer focused on the correctness of the answer and represented four distinct categories - correct, incorrect, self-corrected, or did not answer. Student Explanation reflects categories of students' procedural reasoning strategies previously established by Burns (2012) that are derived from how participants verbally responded to "How did you figure that out?" (Bernbaum Wilmont, 2012). Twenty-six potential categories existed across the ten questions; these responses were subsequently collapsed into four broad categories: 1) used the standard algorithm, 2) used a method specific to the problem other than the algorithm, 3) gave other reasonable explanation, or 4) guessed, did not explain, or gave faulty explanation (henceforth simplified to 'guessed'). See Appendix B for definitions and examples of each type of Student Explanation.

Although the categories of students' reasoning strategies capture students' procedural competence, the measure did not fully capture students' conceptual understanding. Thus, the research team created a construct, Student Reasoning, based on the conceptual understanding reflected in students' verbatim responses and grounded in the literature pertaining to elements of reasoning in mathematics (Dreyfus \& Eisenberg, 1996; English, 2004; Francisco \& Maher, 2010; Kilpatrick et al., 2001). After examining student responses and generating tentative categories, mathematics education experts were consulted for feedback and the categories were refined. Student Reasoning was coded into seven categories: 1) no attempt at reasoning (the student did not answer the problem), 2) guess attempt but incorrect answer (the student answered the problem but said "I don't know " or "I just guessed"), 3) guess attempt and correct answer, 4) partial attempt but had a reasoning breakdown, 5) complete reasoning with a calculation error, 6) complete reasoning and correct answer, or 7) entirely wrong process. See Figure 3 for examples of actual student responses for each MRI category and Appendix $C$ for an operational definition of each category.

\begin{tabular}{|l|l|l|l|l|}
\hline $\begin{array}{l}\text { Type of } \\
\text { Reasoning }\end{array}$ & Question & $\begin{array}{l}\text { Student } \\
\text { Answer }\end{array}$ & $\begin{array}{l}\text { Student } \\
\text { Explanation }\end{array}$ & $\begin{array}{l}\text { Student Verbatim } \\
\text { Reasoning }\end{array}$ \\
\hline $\begin{array}{l}\text { No attempt at } \\
\text { reasoning }\end{array}$ & $7,000 \div 70$ & $\begin{array}{l}\text { Did not } \\
\text { answer }\end{array}$ & N/A & I cannot answer this \\
\hline $\begin{array}{l}\text { Guess attempt, } \\
\text { incorrect }\end{array}$ & $7,000 \div 70$ & $\begin{array}{l}\text { Incorrect } \\
(1,000)\end{array}$ & $\begin{array}{l}\text { Guessed, did not } \\
\text { explain, or gave } \\
\text { faulty } \\
\text { explanation }\end{array}$ & $\begin{array}{l}\text { There's 3 zeros and 7, and } \\
\text { one zero and then a 7, and } \\
\text { the other digit... I don't } \\
\text { really know the answer, I } \\
\text { just guessed }\end{array}$ \\
\hline
\end{tabular}




\begin{tabular}{|l|l|l|l|l|}
\hline $\begin{array}{l}\text { Guess attempt, } \\
\text { correct }\end{array}$ & $1,000-998$ & Correct & $\begin{array}{l}\text { Guessed, did not } \\
\text { explain, or gave } \\
\text { faulty } \\
\text { explanation }\end{array}$ & I don't know \\
\hline $\begin{array}{l}\text { Partial attempt, } \\
\text { reasoning } \\
\text { breakdown }\end{array}$ & $100-18$ & Incorrect (92) & $\begin{array}{l}\text { Guessed, did not } \\
\text { explain, or gave } \\
\text { faulty } \\
\text { explanation }\end{array}$ & $\begin{array}{l}\text { 100 minus } 10 \text { is } 90 \text { and } 90- \\
2, \text { because } 8+2=10, \text { so } 90 \\
+2=92\end{array}$ \\
\hline $\begin{array}{l}\text { Complete } \\
\text { reasoning, } \\
\text { calculation } \\
\text { error }\end{array}$ & $99+17$ & Incorrect (106) & $\begin{array}{l}\text { Used standard } \\
\text { algorithm to add }\end{array}$ & $\begin{array}{l}\text { Added 9 with 7, that's } 16, \\
\text { carried the } 1, \text { and } 9+1 \text { is } \\
10, \text { and there's another } 1, \\
\text { so I added it }\end{array}$ \\
\hline $\begin{array}{l}\text { Complete } \\
\text { reasoning, } \\
\text { correct }\end{array}$ & $15 \times 12$ & Correct & $\begin{array}{l}\text { Gave other } \\
\text { reasonable } \\
\text { explanation }\end{array}$ & $\begin{array}{l}\text { I knew that 12 times } 12 \text { is } \\
144, \text { so I added } 12 \text { three } \\
\text { more times to that }\end{array}$ \\
\hline $\begin{array}{l}\text { Entirely wrong } \\
\text { process }\end{array}$ & $1,000-998$ & Incorrect & $\begin{array}{l}\text { Guessed, did not } \\
\text { explain, or gave } \\
\text { faulty } \\
\text { explanation }\end{array}$ & $\begin{array}{l}\text { Because when you have a } \\
\text { zero plus or minus a number } \\
\text { it is equal to that }\end{array}$ \\
\hline
\end{tabular}

Figure 3. Examples of MRI Responses in Each Category

Next, training and reliability was established between the coders. Two researchers completed reliability on $11 \%$ of the sample with an average of $96 \%$ reliability, and all disagreements were discussed until consensus was reached. Finally, researchers independently coded the remaining $M R I$ interviews. If the participant did not answer the question under the first category, the remaining categories were not coded. Therefore, a maximum of 310 responses could have been coded for this sample at both pretest and posttest. To reiterate, Student Explanation depicts preexisting categories created for the MRI that reflect students' procedural reasoning, whereas the current research team generated the Student Explanation categories to describe students' conceptual understanding.

Descriptive statistics were assessed for frequency of reasoning categories at pre- and posttest, and for EST use over the course of the program. Chi-square analyses were used to determine changes in MRI reasoning categories from pretest to posttest, and the effect size phi was calculated for each analysis. Mann-Whitney $U$ tests were conducted to determine the differences between Grade 3 and Grade 4/5 (data from the three students in Grade 5 were included with Grade 4 because the students were in the same classroom environment). One-way analyses of variance (ANOVAs) were conducted to determine the differences in EST use for the three MRI categories: Student Answer, Student Explanation, and Student Reasoning. Effect sizes (eta-squared) were calculated for all significant group differences as defined by having a $p$-value of less than .05 , and Bonferroni correction was used to conduct post-hoc analyses as needed (Miller, 1981). 


\section{Results}

\section{Descriptive Analyses of EST Use}

Means and standard deviations of electronic support tool use reflect student tool usage over the course of the entire program. On average, students used the audio feature $(M=47.58, S D=$ $55.22)$, calculator $(M=37.84, S D=22.68)$, and notepad $(M=33.90, S D=19.15)$ most often and used the formula $(M=3.27, S D=5.32)$ and the 'need more help' button $(M=5.16, S D=4.70)$ the least. This replicates the findings on frequency of EST use in Crawford et al. (2012), which used the same software program as this study. Descriptive statistics for the frequency of clicks are reported in Table 1.

Table 1. Descriptive Statistics for the Frequency of EST use

\begin{tabular}{lllll}
\hline EST & Min & Max & M & SD \\
\hline Audio & 0 & 207 & 47.58 & 55.22 \\
Key Terms & 0 & 64 & 12.84 & 15.21 \\
Formula & 0 & 17 & 3.23 & 5.32 \\
Calculator & 5 & 114 & 37.84 & 22.68 \\
Need More Help & 0 & 23 & 5.16 & 4.70 \\
Notepad & 8 & 94 & 33.90 & 19.15 \\
Wall & 0 & 34 & 13.35 & 9.94 \\
\hline
\end{tabular}

Chi-square analyses reveal significant changes from pretest to posttest for Student Answer, Student Explanation, and Student Reasoning (see Figure 4). Over the course of the program, students were significantly more likely to answer items correctly and significantly less likely to answer them incorrectly $\left(\chi^{2}=89.374, d f=9, p<.001\right.$; ES $\left.=.54, p<.001\right)$. For Student Explanation, they were more likely to give other reasonable explanations and less likely to use the standard algorithm from pretest to posttest $\left(\chi^{2}=82.007, d f=9, p<.001 ; \mathrm{ES}=.56, p<.001\right)$.

Interestingly, for the category Student Reasoning, significant increases were found for both 'no attempt' at explaining reasoning and complete reasoning with a correct response, and guessing with an incorrect response also significantly decreased from pretest to posttest $\left(\chi^{2}=148.462, d f=\right.$ $36, p<.001 ; \mathrm{ES}=.75, p<.001$ ). Mann Whitney $\mathrm{U}$ tests reveal no differences between Grades 3 and $4 / 5$ on Student Answer, Student Explanation, and Student Reasoning. 


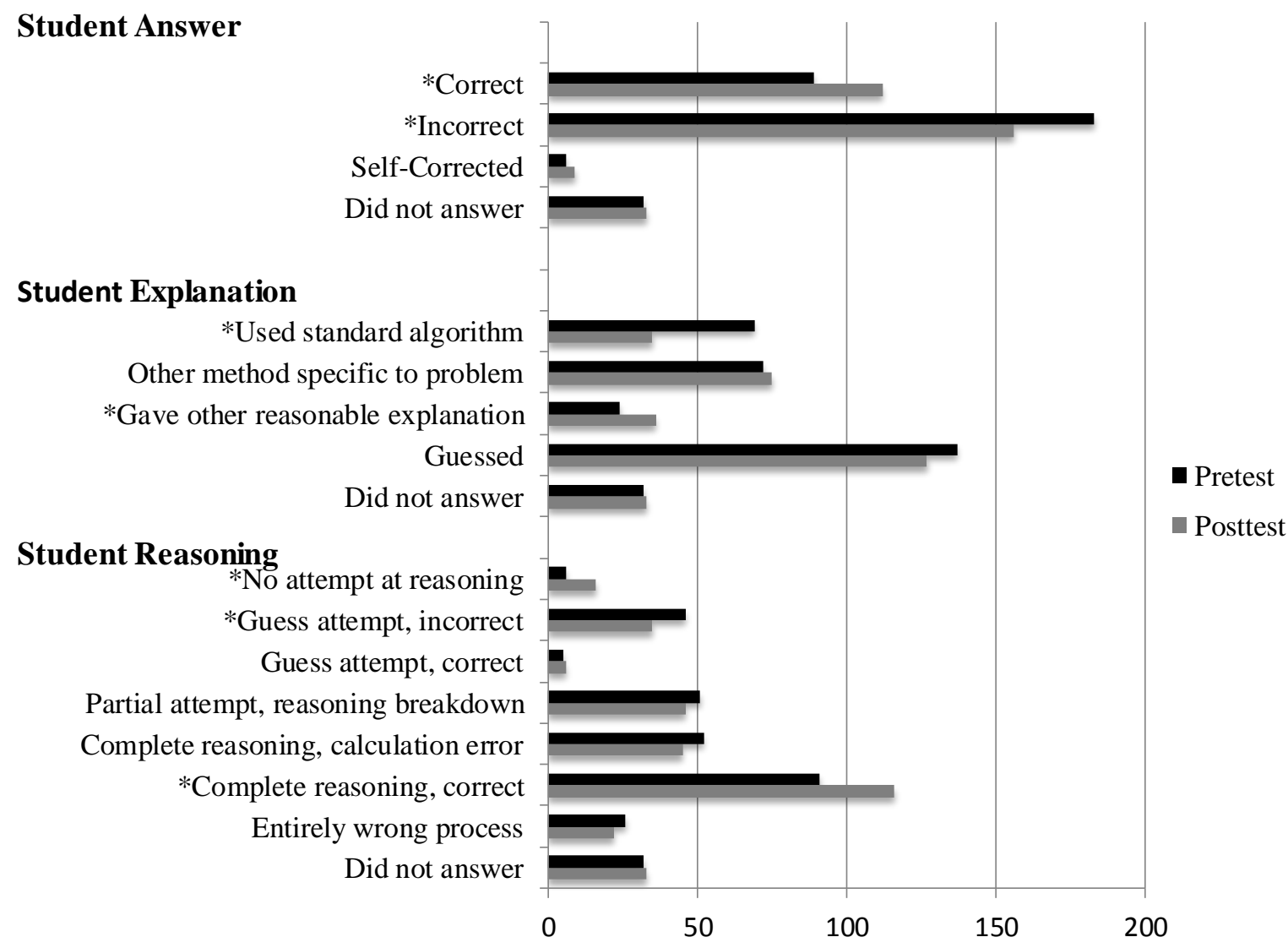

Figure 4. Changes in Mathematical Reasoning from Pretest to Posttest

Note: *Reflects differences between the expected and observed frequencies that have a standardized residual $>1.96$, indicating a significant change from pretest to posttest.

\section{Student Answers and EST Use}

On the MRI pretest, one-way ANOVAs reveal significant differences for all ESTs with the exception of the social media wall. On the MRI posttest, however, there were only significant group differences for the key terms dictionary, 'need more help' button, and the social media wall. Post hoc analyses were conducted for all individual tools when significant differences occurred. Table 2 reports the ANOVA statistics and effect sizes for these data. 
Table 2. One-way ANOVAs for EST Use and Student Answer, Student Explanation, and Student Reasoning

\begin{tabular}{|c|c|c|c|c|c|c|c|c|c|}
\hline & \multicolumn{3}{|c|}{ Student Answer $^{\mathrm{a}}$} & \multicolumn{3}{|c|}{ Student Explanation $^{b}$} & \multicolumn{3}{|c|}{ Student Reasoning ${ }^{c}$} \\
\hline & $F$ & $p$ & $\eta^{2}$ & $F$ & $p$ & $\eta^{2}$ & $F$ & $p$ & $\eta^{2}$ \\
\hline \multicolumn{10}{|l|}{ Pretest } \\
\hline Formula & 5.248 & .002 & .049 & 2.198 & .088 & -- & 1.763 & 107 & -- \\
\hline Audio & 4.333 & .005 & .041 & 5.555 & .001 & .053 & 2.719 & .014 & .057 \\
\hline Key Terms & 18.754 & .000 & .155 & 3.347 & .020 & .033 & .587 & .741 & -- \\
\hline Calculator & 5.103 & .002 & .048 & 1.821 & .143 & -- & 2.256 & .038 & .048 \\
\hline Need Help & 7.705 & .000 & .070 & 2.750 & .043 & .027 & 2.870 & .010 & .060 \\
\hline Notepad & 4.891 & .002 & .045 & 2.544 & .056 & -- & 2.359 & .031 & .050 \\
\hline Wall & 1.237 & .296 & -- & 1.780 & .151 & -- & .794 & .575 & -- \\
\hline \multicolumn{10}{|l|}{ Posttest } \\
\hline Formula & 1.325 & .266 & -- & .455 & .769 & -- & .398 & .880 & -- \\
\hline Audio & 1.643 & .179 & -- & 1.389 & .238 & -- & 2.734 & .013 & .056 \\
\hline Key Terms & 2.742 & .043 & .026 & 2.394 & .051 & -- & 1.203 & .305 & -- \\
\hline Calculator & 2.484 & .061 & -- & 3.995 & .004 & .050 & 2.490 & .023 & .051 \\
\hline Need Help & 4.575 & .004 & .043 & 4.578 & .001 & .057 & 3.884 & .001 & .077 \\
\hline Notepad & .063 & .979 & -- & 1.354 & .250 & -- & 1.281 & .266 & -- \\
\hline Wall & 5.548 & .001 & .052 & 8.175 & .000 & .098 & 3.392 & .003 & .068 \\
\hline
\end{tabular}

Note: The degrees of freedom for Student Answer are 3, 306; for Student Explanation are 3, 298 (pretest) and 4, 302 (posttest); and for Student Reasoning are 6, 270 (pretest) and 6, 279 (posttest).

${ }^{a}$ Student Answer is comprised of four categories: correct, incorrect, self-corrected, and did not answer.

${ }^{b}$ Student Explanation is comprised of four categories: used the standard algorithm, used another method specific to the problem, gave other reasonable explanation, or guessed.

'Student Reasoning is comprised of seven categories: no attempt at reasoning, guess attempt but incorrect answer, guess attempt and correct answer, partial attempt but had a reasoning breakdown, complete reasoning with a calculation error, complete reasoning and correct answer, or entirely wrong process.

Post hoc tests reveal that only two ESTs had significant differences on Student Answer at both pretest and posttest: the key terms dictionary and the 'need more help' button (see Table 3 for means and standard deviations used for post hoc comparisons). At pretest, students who did not answer the items were more likely to use the key terms dictionary than students who answered the items correctly, students who answered the items, and students who self-corrected when answering. At posttest, however, students who answered the item correctly were more likely to use the key terms dictionary than students who did not answer the item, indicating a shift in correctness of answer over the course of the intervention. Also, students who did not answer the items at pretest were more likely to use the 'need more help' button than students who answered the items correctly and students who answered the items incorrectly. This difference remained at posttest for students who did not answer the item and answering correctly but not for incorrect answers. 
Table 3. Means and Standard Deviations of Tool Use for Each Category of Student Answer

\begin{tabular}{|c|c|c|c|c|}
\hline & Correct & Incorrect & Self-Corrected & Did Not Answer \\
\hline Pretest & $N=89$ & $N=183$ & $N=6$ & $N=32$ \\
\hline Formula* & $4.36(6.65)$ & $2.33(4.25)$ & 2.17 (2.99) & $5.38(5.17)$ \\
\hline Audio* & $32.79(47.98)$ & $55.20(59.78)$ & $14.17(13.60)$ & $51.44(27.52)$ \\
\hline Key Terms* & $10.85(13.37)$ & $10.86(11.28)$ & $9.83(14.13)$ & $30.22(24.60)$ \\
\hline Calculator* & $33.21(20.54)$ & $37.92(20.06)$ & $34.67(8.89)$ & $50.81(34.17)$ \\
\hline $\mathrm{NMH}^{*}$ & $4.24(4.10)$ & $5.00(4.03)$ & $5.33(4.27)$ & $8.63(7.26)$ \\
\hline Notepad* & $34.40(16.86)$ & $31.95(17.50)$ & $26.50(9.20)$ & $45.06(27.72)$ \\
\hline Wall & $13.62(9.64)$ & $12.78(9.98)$ & $19.50(9.63)$ & $14.75(9.05)$ \\
\hline Posttest & $N=112$ & $N=156$ & $N=9$ & $N=33$ \\
\hline Formula & $3.21(5.55)$ & $3.01(4.89)$ & $6.56(7.35)$ & $3.42(5.04)$ \\
\hline Audio & $40.93(54.65)$ & $53.33(58.65)$ & $25.67(49.90)$ & $48.94(22.00)$ \\
\hline Key Terms* & $11.43(14.68)$ & $12.41(13.18)$ & $12.56(16.96)$ & $19.73(21.28)$ \\
\hline Calculator & $35.64(22.63)$ & $38.10(21.94)$ & $29.11(14.05)$ & $26.42(23.44)$ \\
\hline $\mathrm{NMH}^{*}$ & $4.43(4.25)$ & $5.32(4.58)$ & 3.00 (3.39) & $7.48(5.57)$ \\
\hline Notepad & $34.33(18.25)$ & 33.66 (19.68) & 31.89 (11.30) & 34.15 (19.32) \\
\hline Wall* & $12.87(9.79)$ & $12.43(9.40)$ & $12.00(8.05)$ & $19.76(10.11)$ \\
\hline
\end{tabular}

Note: $N$ reflects the number of items or instances.

*See text for further description of significant post hoc findings.

Post hoc analyses also indicate that students who answered the items correctly were more likely to use the formulas than students who answered incorrectly, and students who did not answer the items at all were more likely to use the formulas than students who answered incorrectly. Students who did not answer the items were more likely to use the calculator than students who answered the items correctly and students who answered the items incorrectly. Also, students who answered the items incorrectly were more likely to use the audio than students who answered the items correctly. Interestingly, students who did not answer the items were more likely to use the notepad than students who answered the items correctly and students who answered the items incorrectly. For these three particular ESTs (formulas, calculator, and audio), there were no significant differences in tool use on the MRI posttest. On the other hand, there were no significant group differences at pretest for the social media wall; however, at posttest students who did not answer an item were more likely to use the wall than students who answered an item correctly and students who answered incorrectly.

\section{Student Explanations and EST Use}

For the MRI pretest and Student Explanation, significant differences exist between groups for the use of audio and the key terms dictionary (see Table 2). Post hoc analyses reveal that students who guessed (to reiterate, this category captures when students stated "I just guessed," "I don't 
know," or gave a faulty explanation), were more likely to use the audio feature than students who used a method specific to the problem or students who gave another reasonable explanation (see Table 4). This difference was no longer significant at the posttest, however. For the key terms dictionary at pretest, students who used the standard algorithm were more likely to use the key terms dictionary than students who used a method specific to the problem and students who guessed. At posttest, however, students who did not answer the question were more likely to use the key terms dictionary than students who gave another reasonable explanation.

Table 4. Means and Standard Deviations of Tool Use for Each Category of Student Explanation for Post hoc Comparison

\begin{tabular}{|c|c|c|c|c|c|}
\hline & $\begin{array}{l}\text { Standard } \\
\text { Algorithm }\end{array}$ & $\begin{array}{l}\text { Another Method } \\
\text { Specific to } \\
\text { Problem } \\
\end{array}$ & $\begin{array}{c}\text { Other } \\
\text { Reasonable } \\
\text { Explanation } \\
\end{array}$ & Guessed & Did Not Answer \\
\hline Pretest & $N=69$ & $N=72$ & $N=24$ & $N=137$ & $N=32$ \\
\hline Formula & $4.04(5.50)$ & $3.90(6.41)$ & $3.88(5.54)$ & $2.40(4.33)$ & $5.38(5.17)$ \\
\hline Audio* & $46.59(46.76)$ & $32.19(46.74)$ & $28.97(46.63)$ & $60.41(60.98)$ & $51.44(27.52)$ \\
\hline Key Terms* & $17.94(20.56)$ & $11.03(12.86)$ & 13.29 (19.05) & $11.58(11.44)$ & $30.22(24.60)$ \\
\hline Calculator & $42.33(28.99)$ & 33.63 (19.15) & $35.96(17.73)$ & $37.98(21.02)$ & $50.81(34.17)$ \\
\hline $\mathrm{NMH}$ & $6.32(6.00)$ & 4.39 (3.66) & $3.88(2.83)$ & $5.30(4.55)$ & $8.63(7.26)$ \\
\hline Notepad & $39.35(23.98)$ & 32.49 (13.39) & $35.17(19.83)$ & 31.99 (18.28) & $45.06(27.72)$ \\
\hline Wall & $15.54(10.52)$ & $11.78(8.41)$ & $13.33(8.29)$ & $13.18(10.29)$ & $14.75(9.05)$ \\
\hline Posttest & $N=35$ & $N=75$ & $N=36$ & $N=127$ & $N=33$ \\
\hline Formula & $3.14(5.16)$ & $2.61(4.96)$ & $3.42(5.76)$ & $3.24(5.15)$ & $3.42(5.04)$ \\
\hline Audio & $54.69(60.50)$ & $41.55(54.53)$ & $32.75(44.03)$ & $53.06(60.87)$ & $48.94(22.00)$ \\
\hline Key Terms* & $13.26(12.88)$ & $11.52(14.06)$ & $9.33(13.31)$ & $12.66(14.04)$ & $19.73(21.28)$ \\
\hline Calculator* & $45.80(27.77)$ & $32.88(20.68)$ & $31.22(14.87)$ & $38.50(22.17)$ & $26.42(23.44)$ \\
\hline $\mathrm{NMH}^{*}$ & $5.34(4.44)$ & $4.79(4.22)$ & $2.78(2.67)$ & $5.44(4.82)$ & $7.48(5.57)$ \\
\hline Notepad & $39.97(24.00)$ & $33.00(17.05)$ & $35.31(15.66)$ & 32.09 (18.83) & $34.15(19.32)$ \\
\hline Wall & $15.40(11.08)$ & $12.96(9.50)$ & $9.19(6.87)$ & $12.05(9.16)$ & $19.76(10.11)$ \\
\hline
\end{tabular}

Note: $N$ reflects the number of items or instances.

*See text for further description of significant post hoc findings.

No other differences existed at pretest; however, posttests revealed new group differences for some of the students. Students who used the standard algorithm were more likely to use the calculator than students who used another method specific to the problem. Also, students who either guessed or did not answer the problem were more likely to use the need more help feature than students who gave other reasonable explanations. As with Student Answer, there were significant differences for using the social media wall on the posttest. Interestingly, students who did not answer the question were more likely to use the wall than students who used a method specific to the problem, students who gave another reasonable explanation, and students who guessed. This indicates that students who relied on standard methods to solve a problem were using the calculator more frequently, students who did not provide adequate reasoning were 
more likely to use the help feature, and students who did not attempt the problem at all were more likely to use the social media component of the program (see Figure 3 and Appendix B for actual examples of student responses).

\section{Student Reasoning and EST Use}

ANOVAs reveal significant differences between groups for both audio and the 'need more help' button at both pretest and posttest (see Table 2 for ANOVA results and Table 5 for means and standard deviations used in the post hoc analyses; Figure 3 and Appendix $C$ for operational definitions and actual examples of student responses). At pretest, students who guessed at the answers and got them correct were more likely to use the audio feature than students who guessed at the answers but got them incorrect; however, on the posttest, students who guessed incorrectly were more likely to use the audio feature than students who had complete reasoning and answered correctly and students who used the entirely wrong process. This indicates a shift in student behavior over the course of the program. Also, students who guessed and got the answer correct were more likely to use the 'need more help button' than students who guessed and got the answer incorrect and students who had complete reasoning and gave a correct answer on the pretest. Notably, by the posttest, students who made no attempt at the problem (e.g. refused to answer the problem or asked to skip it) were more likely to use the 'need more help button' than students who guessed, students who had complete reasoning but made a calculation error, and students who had complete reasoning and got the problem correct.

Table 5. Means and Standard Deviations of Tool Use for Each Category of Student Reasoning for Post hoc Comparison

\begin{tabular}{lllllllll}
\hline & \multicolumn{1}{c}{1} & \multicolumn{1}{c}{2} & \multicolumn{1}{c}{3} & \multicolumn{1}{c}{4} & \multicolumn{1}{c}{5} & \multicolumn{1}{c}{6} & \multicolumn{1}{c}{7} & \multicolumn{1}{c}{8} \\
\hline \multirow{2}{*}{ Pretest } & $N=6$ & $N=46$ & $N=5$ & $N=51$ & $N=52$ & $N=91$ & $N=26$ & $N=32$ \\
& & & & & & & & \\
Formula & 7.17 & 2.54 & 4.40 & 2.08 & 2.42 & 4.09 & 2.69 & 5.38 \\
& $(7.89)$ & $(4.77)$ & $(6.80)$ & $(4.02)$ & $(4.36)$ & $(6.42)$ & $(4.25)$ & $(5.17)$ \\
Audio* & 29.83 & 69.83 & 28.80 & 53.14 & 49.42 & 31.96 & 50.15 & 51.44 \\
& $(31.26)$ & $(69.58)$ & $(17.20)$ & $(56.15)$ & $(58.19)$ & $(47.89)$ & $(54.62)$ & $(27.52)$ \\
Key Terms & 13.33 & 10.63 & 15.20 & 9.75 & 12.96 & 10.01 & 10.77 & 30.22 \\
& $(11.11)$ & $(10.11)$ & $(10.40)$ & $(9.14)$ & $(14.47)$ & $(12.55)$ & $(11.05)$ & $(24.60)$ \\
Calculator & 32.00 & 34.57 & 52.20 & 34.69 & 42.65 & 32.67 & 38.81 & 50.81 \\
& $(9.10)$ & $(16.11)$ & $(38.96)$ & $(19.20)$ & $(19.85)$ & $(17.87)$ & $(25.55)$ & $(34.17)$ \\
NMH* & 3.83 & 4.54 & 10.40 & 5.14 & 5.37 & 3.90 & 5.46 & 8.63 \\
& $(1.72)$ & $(3.35)$ & $(7.80)$ & $(4.59)$ & $(3.07)$ & $(3.58)$ & $(5.74)$ & $(7.26)$ \\
Notepad & 41.17 & 25.67 & 48.20 & 35.06 & 32.85 & 33.23 & 33.73 & 45.06 \\
& $(32.20)$ & $(14.06)$ & $(32.38)$ & $(16.97)$ & $(17.94)$ & $(15.22)$ & $(20.94)$ & $(27.72)$ \\
Wall & 19.67 & 12.30 & 16.20 & 11.98 & 13.42 & 13.86 & 14.08 & 14.75 \\
& $(7.63)$ & $(9.82)$ & $(10.62)$ & $(10.86)$ & $(8.54)$ & $(9.62)$ & $(11.34)$ & $(9.05)$
\end{tabular}




\begin{tabular}{lllllllll} 
Posttest & $N=16$ & $N=35$ & $N=6$ & $N=46$ & $N=45$ & $N=116$ & $N=22$ & $N=33$ \\
& & & & & & & & \\
Formula & 3.38 & 3.54 & 4.67 & 3.54 & 2.82 & 3.36 & 1.91 & 3.42 \\
& $(5.63)$ & $(5.86)$ & $(6.68)$ & $(5.14)$ & $(4.55)$ & $(5.69)$ & $(3.83)$ & $(5.04)$ \\
Audio* & 51.19 & 76.86 & 65.33 & 45.13 & 49.07 & 38.18 & 30.86 & 48.94 \\
& $(22.68)$ & $(77.06)$ & $(75.12)$ & $(49.03)$ & $(55.02)$ & $(52.92)$ & $(33.77)$ & $(22.00)$ \\
Key Terms & 9.44 & 13.91 & 19.17 & 11.85 & 14.16 & 11.07 & 7.45 & 19.73 \\
& $(4.37)$ & $(15.65)$ & $(22.37)$ & $(10.33)$ & $(15.33)$ & $(14.26)$ & $(5.06)$ & $(21.28)$ \\
Calculator* & 54.25 & 34.80 & 46.50 & 35.30 & 37.98 & 34.50 & 41.82 & 26.42 \\
& $(28.34)$ & $(19.35)$ & $(34.09)$ & $(14.97)$ & $(18.64)$ & $(21.31)$ & $(31.06)$ & $(23.44)$ \\
NMH* & 8.75 & 4.54 & 8.17 & 5.22 & 4.58 & 4.18 & 6.68 & 7.48 \\
& $(6.95)$ & $(4.50)$ & $(7.91)$ & $(33.34)$ & $(2.81)$ & $(3.91)$ & $(6.80)$ & $(5.57)$ \\
Notepad & 26.94 & 28.89 & 27.00 & 37.52 & 33.69 & 34.44 & 34.82 & 34.15 \\
& $(7.35)$ & $(17.19)$ & $(25.25)$ & $(19.26)$ & $(21.26)$ & $(17.35)$ & $(19.72)$ & $(19.32)$ \\
Wall* & 22.44 & 13.46 & 17.50 & 11.74 & 10.84 & 12.72 & 13,55 & 19.76 \\
& $(11.24)$ & $(8.94)$ & $(10.29)$ & $(9.79)$ & $(8.13)$ & $(9.72)$ & $(10.08)$ & $(10.11)$ \\
\hline
\end{tabular}

Note: $N$ reflects the number of items or instances. Student Reasoning is comprised of seven categories: 1) no attempt at reasoning, 2) guess attempt but incorrect answer, 3) guess attempt and correct answer, 4) partial attempt but had a reasoning breakdown, 5) complete reasoning with a calculation error, 6) complete reasoning and correct answer, or 7) entirely wrong process. Category 8 represents unanswered items.

*See text for further description of post hoc findings.

Two other ESTs showed significant group differences at posttest but not at pretest: the calculator and the social media wall. Students who had complete reasoning and answered correctly were more likely to use the calculator than students who made no attempt at the problem. Furthermore, students who made no attempt at the problem were more likely to use the wall than students who guessed incorrectly, students who partially explained their thought process, students who had complete reasoning but a calculator error, and students who had complete reasoning and got the correct answer.

\section{Mathematical Reasoning}

\section{Discussion}

Given the plethora of research indicating the importance of mathematical reasoning (Kilpatrick et al., 2001; NCTM, 2000; NGA \& CCSSO, 2010), findings from this study are consistent with the idea that reasoning itself can be directly taught (Rosenstein et al., 1996) and technologies can be used to enhance reasoning (Kramarski \& Zeichner, 2001; Mevarech \& Kramarski, 1997; O’Donnell, 2006; Yian-Shu et al. , 2014). Overall, students showed improvement in their answers, explanations, and reasoning after interacting with the MLC program. Results denote more correct answers on the posttest than the pretest, more students were giving other reasonable explanations, and fewer were using the standard algorithm on the posttest, indicating a shift in procedural understanding of the mathematical concepts. As anticipated, fewer students were guessing incorrectly and more were giving correct responses with complete reasoning on the posttest, indicating an overall shift from weaker to stronger conceptual reasoning skills over the course of the program as well. This finding is consistent with studies that show different ways that support tools embedded in technologies can be used to positively impact reasoning skills (Aleven et al., 2006; Crawford et al., 
2012; Crawford et al., under review). Unexpectedly, however, significantly more students chose not to provide any reasoning on the posttest than on the pretest. This could be due to a lack of confidence about their answers that was not present at pretest or an awareness of an inability to correctly answer the problem. Students may have learned enough over the course of the intervention to know when their reasoning was incomplete; however, they had not learned enough to confidently make an educated guess at the answer. These results may indicate that a shift in students' thinking occurred over the course of the intervention.

\section{Relationship of Correctness of Response to EST Use}

Being able to provide correct responses to problems is essential to students' procedural fluency in mathematics (Kilpatrick et al., 2006). Within this study, frequency of EST use throughout the program reflects how students use the tools to maximize the potential benefits of the program. Generally, students who were more likely to give correct answers at pretest were less likely to use the ESTs than students who either answered the item incorrectly at pretest or students who chose not to answer the item, with the exception of the formulas and the social media wall. At posttest, however, students who answered correctly were more likely to have used the key terms dictionary. Students who did not answer were more likely at both pre- and posttest to use the tools than students who answered either correctly or incorrectly, indicating a possible lack of knowledge, reasoning, and/or confidence about answering the question. These findings appear to mirror findings from other studies with respect to how and why students access specific types of ESTS. For example, Renkl (2002) reported the effects of a "help feature" for solving probability problems in mathematics. Those in the treatment condition who had access to the "help feature" scored significantly better on the post-test than those in the control group. Additionally, Aleven et al. (2006) found that students' math scores improved when they used help tools effectively.

\section{Relationship of Student Explanation and Reasoning to EST Use}

For Student Explanation, students who gave other reasonable explanations or used a method specific to the problem on the MRI were less likely to use tools at both pre- and posttest than students who guessed, used the standard algorithm, or did not initially answer the problem. This reflects the idea that students who already have procedural understanding of these concepts may not need the tools as much as students who are unfamiliar with the mathematical procedures (Kilpatrick et al., 2006). The differences in Student Reasoning reveal that students who were guessing correctly at the pretest were more likely to use the audio feature and the 'need more help' button. At posttest these differences shifted to students guessing incorrectly or making no attempt at reasoning. This demonstrates how students with weaker conceptual reasoning skills (e.g. making no attempt, guessing) are more likely to use ESTs than students with stronger conceptual reasoning skills (e.g. complete reasoning with either a correct or incorrect answer).

These findings expand on the differences in tool use found in previous research by showing how students use ESTs to individualize the program based on their prior ability to reason through a problem (Aleven et al., 2006; Crawford et al. 2012; Crawford et al., under review). Students who enter the program with weaker reasoning skills, demonstrated by either guessing or not 
attempting the problem, are more likely to use a variety of ESTs than students who enter with stronger reasoning skills. The results also support previous studies that demonstrate how technologically-based programs can enhance students' mathematical reasoning (Kramarski \& Zeichner, 2001; Yian-Shu et al., 2014), expanding on this idea by focusing specifically on EST use in mathematics.

\section{Limitations}

Several limitations for the current study need to be addressed. The sample size was small and from two private schools; because public and private schools take different approaches to mathematics education, the generalizability of this study is limited. The public school curriculum is largely governed by decisions at the state and school district level; however, private schools can make curriculum decisions at a building level. Therefore, the curricula that are implemented and the nature of the instruction may look very different a public and a private school. Also, students did not complete the same curriculum across classrooms and grade levels, thus some of the observed effects could be confounded by the curriculum itself.

Although the MRI is a validated measure, the Student Reasoning category was developed by the researchers for this study and is subjective in nature; thus, it needs to be validated across several studies. Also, the specific ESTs measured in this study represent only a few ESTs available outside of MLC, and (with the exception of the 'need more help' button) were available to the students at all times during the program. Therefore, although strong associations are made in this study between EST use and reasoning, it is difficult to draw definitive conclusions regarding reasoning and the use of ESTs. Finally, other measures of mathematical achievement could provide further insight into student's EST usage beyond mathematical reasoning.

\section{Implications for Future Research}

The current study demonstrates how the use of ESTs can enhance students' mathematical reasoning because students are able to individualize a technology-based program to meet their own needs. Also, students showed improvement in reasoning across the course of the program, which is related to their EST use. The results of this study present a unique contribution to the field of educational technology by providing specific details on how students are using specific aspects of educational programs to maximize their learning. Students tailor the program to their specific needs, which allows for an increase in their mathematical reasoning as well as obtaining the correct response.

These findings lay the groundwork to both replicate and expand upon this study. Future studies are needed to validate the Student Reasoning category of the MRI, and future research could expand upon this work with a stronger design, such as a randomized control trial, and a larger sample of students. Also, research conducted in public schools would be necessary for the generalizability of these findings across school settings. The results of the current study provide a rationale for examining subgroups (e.g. students with disabilities, students of different levels of access to technology at home, students with high versus low computer self-efficacy or reasoning) 
of students' use of ESTs as well. Because students use ESTs to tailor the program to their individual needs, future research could examine similarities and differences across subgroups of students on their use of technological tools. Furthermore, individuals who design computer-based education programs can use the findings of this study to embed active features that allow students to maximize their learning from the program. Because each tool is used differently by different learners to enhance their reasoning, the findings highlight the importance of embedding a variety of tools within computer-based curricula.

\section{Conclusion}

The findings from this study emphasize one way in which technology can enhance students' mathematical procedural and conceptual reasoning, which has been proven essential for overall mathematical proficiency (NGA \& CCSSO, 2010; NCTM, 2000). Specific aspects of technology, such as electronic support tools, can give rise to changes in mathematical reasoning and furthering mathematical procedural and conceptual understanding. By improving mathematical proficiency and furthering engagement with technology, students' become more competitive as future workers in the overall global economy (OECD, 2013a).

\section{Acknowledgements}

This research was supported in part by the Mathematics eText Research Center (MeTRC) at the University of Oregon. MeTRC is funded by the U.S. Department of Education, Office of Special Education Programs (Award Number H327H09090002), and a team of MeTRC researcher assisted with the design and implementation of this project. Research was also supported, in part, by the National Center for Special Education Research, Institute of Education Sciences (Award Number R324A090340), who did not have any part in the design and implementation of the study or the writing of this manuscript.

\section{References}

Aleven, V., McLaren, B.M., Roll, I., \& Koedinger, K.R. (2006). Toward meta-cognitive tutoring: A model of help seeking with a Cognitive Tutor. International Journal of Artificial Intelligence in Education, 16, 101-128.

Anderson-Inman, L. \& Horney, M. (1996). Computer-based concept mapping: Enhancing literacy tools for visual thinking. Journal of Adolescent \& Adult Literacy, 40, 302-306.

Bernbaum Wilmont, D. (2012). Math reasoning inventory. (Technical Report) Sausalito, CA: Math Solutions, Scholastic.

Burns, M. (2012). Math reasoning inventory. Retrieved July 22, 2013 from www.mathreasoninginventory.com

Crawford, L., \& Freeman, B. (2011). The Math Learning Companion: Initial research into two curriculum components. Presentation at Society for Research on Educational Effectiveness. Washington D.C., September 8-10, 2011. 
Crawford, L., Higgins, K., \& Freeman. B. (2012). Exploring the use of computer based electronic support tools by students with learning disabilities. Learning Disabilities: A Multidisciplinary Journal, 18(3), 135-144.

Crawford, L., Higgins, K., D’Angelo, J. \& Hall, L. (2016). Use of active electronic support tools in mathematics. Manuscript under review.

D’Angelo, J., Higgins, K., \& Crawford, L. (2016). Technology, affective characteristics and mathematics: A review of the literature from 1985-2013. Manuscript under review.

Digital Directions International (2005). HELPMath. Retrieved July 2, 2014 from http://www.helpprogram.net

Digital Directions International (2013). Math Learning Companion. Retrieved July 2, 2014 from www.mathlearningcompanion.net

Englert, C., Manalo, M., \& Zhao, Y. (2004). I can do it better: The effects of technology enabled scaffolding on young writers' composition. Journal of Special Education Technology, 19(1), 522.

Francisco, J. M., \& Maher, C. A. (2010). Teachers attending to students' mathematical reasoning: Lessons from an after-school research program. Journal of Mathematics Teacher Education, 14(1), 49-66.

Hanushek, E.A., Peterson, P.E., \& Woessman, L. (2012). Achievement growth: International and U.S. state trends in student performance. Program on Education Policy \& Governance report No: 12-03. Cambridge, MA: Harvard Kennedy School.

Kilpatrick, J., Swafford, J., \& Findell, B. (Eds.). (2001). Adding it up: Helping children learn mathematics. Washington, DC: National Academy Press.

Kramarski, B., \& Zeichner, O. (2001). Using technology to enhance mathematical reasoning: Effects of feedback and self-regulation learning. Educational Media International, 38(2/3), 77-82.

Mevarech, Z.R. \& Kramarski, B. (1997). IMPROVE: A multidimensional method for teaching mathematics in heterogeneous classrooms, American Educational Research Journal, 34, 365-394.

Miller, R.G. (1981). Simultaneous statistical inference. 2nd ed. (pp. 6-8), New York NY: SpringerVerlag.

National Council of Teachers of Mathematics. (2000). Principles and Standards for School Mathematics. Reston, VA: Author.No Child Left Behind [NCLB] Act of 2001, Pub. L. No. 107110, 115, Stat. 1425 (2002).

National Council of Teachers of Mathematics. (2009). Guiding principles for mathematics curriculum and assessment. Retrieved on August 11, 2014 from http://www.nctm.org/standards/content.aspx?id=23273

National Governors Association Center for Best Practices \& Council of Chief State School Officers. (2010). Common Core State Standards for Mathematics. Washington, DC: Authors.

Organisation for Economic Co-operation and Development. (2013a). Lessons from PISA 2012 for the United States, Strong Performers and Successful Reformers in Education. Retrieved on 
September 9, 2014 from http://dx.doi.org/10.1787/9789264207585-en

Organisation for Economic Co-operation and Development. (2013). PISA 2012 Results: What Makes Schools Successful? Resources, Policies and Practices (Volume IV). Retrieved on September 10, 2014 from http://dx.doi.org/10.1787/9789264201156-en

O'Donnell, A.M. (2006). Introduction: Learning with technology. In A.M. O'Donnell, C.E. HmeloSilver, \& G. Erkens (Eds.) Collaborative learning, reasoning, and technology (pp. 1-14), Mahwah, NJ: Lawrence Erlbaum Associates.

Reasoning [Def. 1]. (2014) Merriam Webster Online. Retrieved July 7, 2014, from http://www.merriam-webster.com/dictionary/reasoning

Renkl, A. (2002). Worked-out examples: Instructional explanations support learning by selfexplanations. Learning and Instruction, 12, 529-556.

Rosenstein, J.G., Caldwell, J.H., \& Crown, W.D. (1996). New Jersey Mathematics Curriculum Framework: A collaborative effort of the New Jersey Mathematics Coalition and the New Jersey Department of Education. New Brunswick, NJ: The New Jersey Mathematics Coalition, Rutgers, The State University of New Jersey.

Tran, Z. (2005). Help with English Language Proficiency "HELP" program evaluation of sheltered instruction multimedia lessons [White paper]. Retrieved from www.helpprogram.net

U.S. Department of Education, Office of Educational Technology. (2010). Transforming American Education: Learning Powered by Technology, Washington, D.C.: U.S. Department of Education.

Yian-Shu, C., Haw-Ching, Y., Shian-Shyong, T., \& Che-Ching, Y. (2014). Implementation of a modeltracing-based learning diagnosis system to promote elementary students' learning in mathematics. Journal of Educational Technology \& Society, 17(2), 347-357.

Correspondence: Kristina N. Higgins, Assistant Professor, Department of Curriculum and Instruction, College of Education, Tarleton State University, Fort Worth, Texas, United States 
Appendix A

MLC Lessons Completed by Each Class

School 1

Grade $3(n=9)$

- MF1 L1 - Place Value

- MF1 L2 - Addition \& Subtraction

- MF1 L6-Decimals \& Money

- MF1 L3-Multiplication

- MF1 L4-Division

- MF1 L5 - Fractions

- MF1 L8-Geometry

- MF1 L7-Measurement

Grades 4 \& $5(n=8)$

- MF1 L7-Measurement

- MF1 L8-Geometry

- MF2 L2 - Fractions \& Decimals

- MF2 L2 - Perimeter \& Area

- MF2 L2-Geometry

- MF3 L6 - Division Skills

- MF3 L8-Add \& Subtract Fractions

- $\quad$ Alg L1 - Interpreting Graphs

School 2

Grade $3(n=7)$

- MF1 L1 - Place Value

- MF1 L2 - Addition \& Subtraction

- MF1 L3-Multiplication

- MF1 L4-Division

- MF1 L5 - Fractions

- MF1 L6 - Decimals \& Money

- MF1 L7-Measurement

- MF1 L8-Geometry

Grade $4(n=7)$

- MF1 L3 - Multiplication

- MF1 L4-Division

- MF1 L5 - Fractions

- MF2 L1 - Place Value

- MF2 L2 - Fractions \& Decimals

- MF2 L4-Addition \& Subtraction

- MF2 L5 - Multiplication

- MF2 L10 - Perimeter \& Area 


\section{Appendix B \\ Definitions of Student Explanation*}

- No Attempt - student does not answer the problem, therefore s/he does not provide any explanation

Example Response: “Can I skip this one?"

- Used Standard Algorithm - student provides the standard algorithm to add, subtract, multiply, or divide when solving the problem

Example Response: Problem is 1,000 - 998, student responds, "I put the 998

under the 1,000, and then I cross out the 1 and put a 0 , then cross out the next 0 and put a 9 , and cross out the next one and put a 9 , and the last 0

becomes a 10, and then $10-8$ is 2 , and $9-9$ is 0 , and $9-9$ is 0 , so the answer is

2."

- Other Method Specific To Problem - student uses a strategy to solve the problem predetermined by the MRI that is specific for the problem

Example Response: Problem is $100-18$, predetermines strategies are 1) Added up from 18 to 100, 2) Subtracted 20 and then added 2, or 3) subtracted 10 and then subtracted 8 . Student response, "I did 100 minus 10 which is 90 , and then I did 90 minus 8 and I got $82 . "$

- Gave Other Reasonable Explanation - student gave an explanation that provided sufficient reasoning but was not listed in the predetermined strategies

Example Response: Problem is $15+\ldots=200$, student responds, "I knew that 5 $+5+5$ is 15 , so I did $200-5$ and got 195 , minus 5 is 190 , minus 5 again is 185 ."

- Guessed, Did Not Explain, or Gave Faulty Explanation - student stated that they guessed at the response, did not explain their reasoning, or gave reasoning that was incomplete or incorrect

Example Response: Problem is $15 \times 12$, Possible student responses could be, "I don't know, I just guessed." "I have no idea." "I think I do $5 \times 2$ is 10 and $1 \times 1$ is 1 so it is $100 . "$

*These categories are based on categories previously created by Burns (2012). 


\section{Appendix C \\ Operational Definitions of Student Reasoning Created by Research Team}

- No Attempt - student does not answer the problem, therefore s/he does not provide any reasoning

Example Response: "Can I skip this one?"

- Guess, Incorrect - students answers the problem incorrectly, but does not provide any or adequate reasoning

Example Response: "I just guessed." "I have no idea." "I think it's 100 minus something."

- Guess, Correct - student answers the problem correctly, but does not provide any or adequate reasoning

Example Response: Problem is $25 \times 4$, student responds, "I'm not sure, but I'm thinking about 100."

- Partial Attempt, Breakdown in Process - the student begins to communicate mathematical reasoning; however, reasoning is incomplete or incoherent

Example Response: Problem is 100-18, student responds, "Took away 10 and then did 8, 9, 10 so I knew it was 2"

- Complete, Calculation Error - the student communicates their reasoning coherently; however they make a calculation error along the way

Example Response: Problem is 100-18, student responds, "Because 100-10 is 90, and then you take 8 more away, and $10-8$ is $1 . "$

- Complete, Correct - the student communicates their reasoning completely and coherently with a correct response

Example Response: Problem is $60 \times 40$, student responds, "I took away the zeros and did $6 \times 4$ and got 24 , and then added back the zeros and its $2,400 . "$

- Entirely Wrong Process - the student communicates their reasoning completely and coherently, but performs the wrong operation or describes a logically incorrect process

Example Response: Problem is 1,000 - 998, student responds, "I added 998 to 1,000 and I got 1,998." 